\title{
Effects of presentation, recall, and study trials on word recall of a highly structured list
}

\author{
ROBERT L. HUDSON and KATHLEEN S. HUDSON \\ Mississippi State University, Mississippi State, Mississippi 99762
}

\begin{abstract}
Groups differing in the pattern of presentation, recall, and study trials were compared on common postinput recall trials for number of words recalled. The major hypothesis was that a highly structured list would result in differences where they had not been previously found. The hypothesis was not supported for either a group given no cuing or a group given cuing.
\end{abstract}

There have been several studies (Donaldson, 1971; Hudson, Solomon, \& Davis, 1972; Rosner, 1970; Simmons, 1973; Tulving, 1967) which have modified the usual multitrial free recall (MTFR) analysis of alternating presentation $(P)$ and recall $(R)$ periods. All of these studies have demonstrated the influence of $\mathbf{R}$ periods to be as great as that of $\mathbf{P}$ periods on gross dependent variables such as number of words recalled even though more detailed analyses have indicated differences in some components of total recall. In short, within broad limits, it seems to make no difference how sequences of $P$ and $R$ trials are arranged and how the total time spent on each is divided as long as the dependent variable is total recall on an immediate postpresentation recall.

Rosner (1970) has suggested that $R$ periods in MTFR facilitate organization to a greater extent than do $P$ periods. This would seem to suggest that the lack of difference in a PRPR group and a PRRR group is the result of different underlying processes. Support for that notion was found by Hudson et al. (1972). The evidence would suggest that the PRRR group is able to recall words partly because of a high degree of organization and that the PRPR group is able to recall words because, even though the $\mathbf{P}$ trial results in interference and disruption of organization, it also presents words that are, in effect, new.

It would seem to follow that if the list of words used was highly structured so that organization was relatively simple to maintain, a PRPR group would exceed a PRRR group on postinput $R$ trials.

Lachman and Mistler (1970) have presented evidence to suggest the importance of an $\mathrm{R}$ trial is simply the activation of what they call the item-generating system. In other words, it is the activity of mentally searching for words that is important to an R trial. Accordingly, the present study is designed to determine what effect the elimination of active recall after the first $R$ period in a PRRR group will have relative to a standard PRRR group. This will be done by simply instructing one group that the trials of a cycle will consist of (a) presentation trial, (b) recall trial, (c) study of recall in b, and (d) study of recall in $b$. This group will be called a PRSS group.
Since it was necessary that all words be presented together on P trials, rather than individually, there was also a PPPR group to determine if the change in methodology affected the relative difference between groups differently than that of Hudson et al. (1972).

Combined orthogonally with these four groups were two levels of cuing, that is, either present or absent. The four cued groups were included because cuing further increases the ease of organization of an organized list, and it would be possible to determine if there were any interactions between cue (present or absent) and the four conditions.

\section{METHOD}

\section{Subjects}

The subjects were 120 male and female undergraduate students enrolled in introductory psychology classes at Mississippi State University.

\section{Materials}

The stimulus list employed consisted of four nouns from each of 10 categories, selected from the category norms of Battig and Montague (1969). The specific words and categories used were identical to those used by Simmons (1973).

Booklets prepared for the subjects contained general instructions which were the same for all groups. The instructions included a description of the nature of the experiment, a statement of what the subject was expected to do, and the general format, that is, 14 trials consisting of $P$ trials, $R$ trials, and/or $S$ trials, each $80 \mathrm{sec}$ long.

A second part of the general instructions was different for each group and informed the subject regarding the particular sequence of $\mathbf{P}, \mathbf{R}$, or $\mathrm{S}$ trials that he would receive. For those subjects in cued groups, the instructions stated that the words could be categorized and the categories named.

On the $P$ page in each booklet were typed the 40 words, double spaced, in two columns. The 40 words were randomized by category, and were further randomized within a category. All words from a given category did, however, appear consecutively. There were 10 such random orders generated, so that no subject received the same order twice. All booklets were formed using these 10 orders.

The $R$ page for the noncued groups consisted of 40 blank lines divided into two columns of 20 lines each. For the cued groups the category names were printed on the $R$ page with four blank lines under each category name. Thus, there were two columns on that page, each consisting of five category 
names and four blank lines under each name, for a total of 20 lines per column.

There were no separate sheets for $S$ trials. The subjects were simply instructed to study the words that they had just recalled on the most recent $\mathrm{R}$ trial.

The booklets were assembled with appropriate instructions, with $R$ and $P$ pages in the order required for each condition. They were then arranged in a random order in blocks of eight for distribution.

\section{Procedure}

The subjects were tested in five groups of approximately 24 subjects each, and each subject was randomly assigned to one of eight conditions as described above. The subjects were told to open their booklets and read the instructions printed therein. They were informed that the experiment was divided into 14 blocks of $80 \mathrm{sec}$ each, and that they would not all be doing the same thing in a given block of time. They were instructed that the experimenter would signal when to begin each time block. The first page in each booklet listed all 14 blocks of time and instructed the subject regarding what he would be doing during each time block.

Each of the $10 \mathrm{P}$ orders was used at least once and no more than twice for the first $P$ trial in assembling the 15 booklets for each group. For each booklet the $P$ order for each $P$ trial following the first was chosen at random without replacement.

The 40 words were simultaneously exposed on a $P$ trial for a total of $80 \mathrm{sec}$ per $P$ trial. The $R$ trials and the $S$ trials were likewise $80 \mathrm{sec}$ long. The beginning of each trial was signaled by the experimenter. Intertrial intervals were approximately $5 \mathrm{sec}$. Booklets were collected following the final $\mathrm{R}$ trial.

\section{RESULTS}

Table 1 presents the mean number of words recalled in the eight conditions on each $\mathbf{R}$ trial. The item recall scores on common immediate postinput $\mathbf{R}$ trials (Trials 2, 6, 10, and 14) for all groups except Groups PPPR and PPPR(c) were examined by a 2 by 3 by 4 split-plot factorial analysis of variance. The analysis indicated a significant cuing effect (CE) $[F(1,84)=$ $11.57, \mathrm{p}<.01]$, a significant trial effect $(\mathrm{T})[\mathrm{F}(3,252)=$ $361.28, p<.01]$, a significant $T$ by $C E$ effect $[F(3,252)=$ $3.95, \mathrm{p}<.01]$, and a significant Trials by Treatment Conditions (C) interaction $[\mathrm{F}(6,252)=2.44, \mathrm{p}<.05]$. The $\mathrm{F}$ ratios for $\mathrm{C}, \mathrm{C}$ by $\mathrm{CE}$, and $\mathrm{T}$ by $\mathrm{CE}$ by $\mathrm{C}$ were less than 1.00 . The $T$ by $C E$ interaction was examined for simple main effects comparing the two levels of cuing at each of the four trials. The results were as follows: Trial 2, $\mathrm{F}(1,336)=1.21, \mathrm{p}>.05 ;$ Trial 6, $\mathrm{F}(1,336)=9.40, \mathrm{p}<.01$, Trial 10, $\mathrm{F}(1,336)=12.26$, $\mathrm{p}<.01$, and Trial 14, $\mathrm{F}(1,336)=14.69, \mathrm{p}<.01$. The $\mathrm{T}$ by $\mathrm{C}$ interaction was examined for simple main effects by comparing the three treatment conditions at each of the four trials. None of the resultant $F$ values was significant at the .05 level. The significant interaction resulted from a less rapid rate of increase for the PRSS group.

\section{DISCUSSION}

Analysis of the data indicates no differences in recall between any of the groups within the cued condition or between any of the groups within the noncued condition. Thus, the hypothesis that a highly structured list would result in an advantage for the PRPR group was not supported.

Since no significant differences were noted between groups in the noncued condition on total words recalled, the results of this experiment indicate that the change in methodology did not effect the comparative results of Hudson et al. (1972). Hudson et al. presented 40 similar words from the norms of Battig and Montague (1969) which could also be grouped into categories. The words were presented one at a time for $2 \mathrm{sec}$ per word. Thus, the total time of $80 \mathrm{sec}$ spent on $\mathbf{4 0}$ words was equal for the Hudson et al. study and for the present study. Additionally, Hudson et al. used Groups PRPR, PPPR, and PRRR. Although the data from Group PPPR were not included in the present analysis because of conflicting immediate postpresentation $\mathbf{R}$ trials, inspection of Table 1 clearly indicates that there are no significant postpresentation differences between any of the groups.

On any given trial the number of words recalled by all of the noncued groups in the present study was greater than the number of words recalled in the study by Hudson et al. (1972). This is most likely because Hudson et al. presented the stimulus list in completely random order, while in the present study the words were presented randomly within a category, but all words from any given category were presented together.

The significant Trials by Treatment Condition interaction does indicate the possibility that the PRSS group performed more poorly than either the PRPR or PRRR groups, even though simple main effects analyses comparing the three groups at each trial were nonsignificant. This resulted from the PRSS and PRSS(c) groups recalling more words (although not significantly more) in Period 2, at which time these groups had not been treated differently from the other groups. Thus, a replication of this study might very well result in the PRSS group performing significantly more poorly in later trials. Implications of this, however, will not be pursued until the evidence is presented.

Table 1

Means of Total Words Recalled

\begin{tabular}{|c|c|c|c|c|c|c|c|c|c|c|}
\hline \multirow[b]{2}{*}{ Group } & \multicolumn{10}{|c|}{ Number of Period* } \\
\hline & 2 & 3 & 4 & 6 & 7 & 8 & 10 & 11 & 12 & 14 \\
\hline $\begin{array}{l}\text { PRPR } \\
\text { PPPR }\end{array}$ & 19.27 & & $\begin{array}{l}24.60 \\
24.73\end{array}$ & 26.40 & & $\begin{array}{l}29.27 \\
31.53\end{array}$ & 31.00 & & $\begin{array}{l}32.60 \\
33.80\end{array}$ & $\begin{array}{l}32.47 \\
33.53\end{array}$ \\
\hline $\begin{array}{l}\text { PRRR } \\
\text { PRSS }\end{array}$ & $\begin{array}{l}17.20 \\
20.87\end{array}$ & 17.93 & 17.87 & $\begin{array}{l}26.53 \\
27.93\end{array}$ & 25.47 & 25.80 & $\begin{array}{l}29.07 \\
31.53\end{array}$ & 28.33 & 28.67 & $\begin{array}{l}30.47 \\
31.67\end{array}$ \\
\hline $\begin{array}{l}\text { PRPR(c) } \\
\text { PPPR(c) }\end{array}$ & 20.80 & & $\begin{array}{l}27.80 \\
27.47\end{array}$ & 31.73 & & $\begin{array}{l}32.60 \\
32.27\end{array}$ & 34.93 & & $\begin{array}{l}35.33 \\
34.93\end{array}$ & $\begin{array}{l}36.67 \\
36.00\end{array}$ \\
\hline $\begin{array}{l}\text { PRRR(c) } \\
\text { PRSS(c) }\end{array}$ & $\begin{array}{l}18.87 \\
21.20\end{array}$ & 19.07 & 20.47 & $\begin{array}{l}30.47 \\
28.53\end{array}$ & 30.27 & 30.53 & $\begin{array}{l}33.47 \\
34.47\end{array}$ & 33.27 & 33.40 & $\begin{array}{l}36.40 \\
33.87\end{array}$ \\
\hline
\end{tabular}

*Periods $1,5,9$, and 13 are not reported since all groups received $P$ trials in these periods. 


\section{REFERENCES}

Battig, W. F., \& Montague, W. E. Category norms for verbal items in 56 categories: A replication and extension of the Connecticut category norms. Journal of Experimental Psychology Monographs, 1969, 80(No. 3, Part 2), 1-45.

Donaldson, W. Output effects in multitrial free recall. Journal of Verbal Learning and Verbal Behavior, 1971, 10, 577-585.

Hudson, R. L., Solomon, M. L., \& Davis, J. L. Effects of presentation and recall trials on clustering and recall. Journal of Verbal Learning and Verbal Behavior, 1972, 11, 356-361.

LAChMAN, R., \& MistleR, J. L. Rehearsal, test trials, and component processes in free recall. Journal of Experimental Psychology, 1970, 85, 374-382.

ROSNER, S. R. The effects of presentation and recall trials on organization in multitrial free recall. Journal of Verbal Learning and Verbal Behavior, 1970, 9, 69-74.

Simmons, J. F. Patterned vs. unpatterned sequences of study and recall trials in free recall of a categorizable word list. Journal of Experimental Psychology, 1973, 101, 191-193.

Tulving, $E$. The effects of presentation and recall of material in free-recall learning. Journal of Verbal Learning and Verbal Behavior, 1967, 6, 175-184.

(Received for publication February 28, 1977.) 